\title{
DIE UITDAGINGS VERBONDE AAN DIE \\ LEWERING VAN PRIMÊRE GESONDHEIDSORGDIENSTE \\ IN ARTIKEL 30-GEBIEDE
}

\author{
DELENE MCNULTY \\ ORGANISEERDER VAN VERPLEEGDIENSTE - \\ DEPARTEMENT VAN GESONDHEID, \\ WELSYN EN PENSIOENE
}

\begin{abstract}
SUMMARY
Article $\mathbf{3 0}$ areas are those in which the Department of Health, Welfare and Pensions act as the local authority in terms of health services. The Department has been developing comprehensive primary health care services, provided by registered nurses, in these areas since 1975.

These services are challenged by complex problems and methods for primary health care used successfully in other areas are inappropriate. As those served are mostly immigrant farm labourers, village workers cannot be used. A lack of demographic and epidemiological data complicates the setting of objectives and thus planning of services. There are few clinic services and supportive services and sources for referral are inadequate or non-existent.

The nurse mostly provides the service from a car at suitable central points. Sophisticated technology cannot be used and equipment, techniques and procedures must be carefully selected or even improvised.

The success of the service depends on the nurses' ability to gain the co-operation and acceptance of the farmer who is the employer; doctors and pharmacists; school principals; magistrates; the nearest hospitals which may be in another country; and of the target group comprising the workers and their families.

In this time of fragmentation and specialised care in health services the nurses providing the section 30 services must be able to meet all promotive, preventive, curative and rehabilitative health needs - she is expected to be a model of versatility.
\end{abstract}

\section{INLEIDING}

$\mathbf{K}^{\mathrm{n}}$ ragtens delegasie ingevolge artikel 50(2) van die Wet op Gesondheid 63 van 1977, tree die Departement van Gesondheid, Welsyn en Pensioene op as die plaaslike bestuur in daardie gebiede waar daar geen ander plaaslike bestuur is nie - die artikel 30 -gebiede.

In 134 plattelandse distrikte in die Transvaal, Oranje-Vrystaat en Natal behartig die Departement van Gesondheid, Welsyn en Pensioene dus benewens sy ander pligte ook sy pligte as plaaslike bestuur en oefen hy sy bevoegdhede uit aangesien daar in hierdie gebiede geen ander plaaslike bestuur is nie.

Die eertydse Departement van Gesondheid het reeds ingevolge die ou Volksgesondheidswet 36 van 1919, soos gewysig, hierdie verpligting gehad. Tot betreklik onlangs was hierdie dienste egter beperk tot omgewingsgesondheid, immunisering, die behandeling van tuberkulose en gesondheidsvoorligting

Die konsep van 'n omvattende primêre gesondheidsorgdiens vir hierdie landelike gemeenskappe, het gekulmineer in die Inspeksieverslag van die
Staatsdienskommissie (nou die Kommissie vir Administrasie) wat in 1975 aanvaar is (die Rheederverslag). Genoemde verslag het voorsiening gemaak vir spanne verpleegkundiges om mobiele primêre gesondheidsorgdienste (P.G.S.) in die areas waarvoor die Departement verantwoordelik is, te lewer. Daar is in 1976 begin om hierdie poste te vul en om die dienste te ontplooi.

\section{ELEMENTE VAN DIE DIENS}

Die Departement sal, as ' $n$ interimmaatreël, voorgeboortesorg en die behandeling van geringe ongesteldhede in hierdie gebiede lewer. Hierdie dienste is die verantwoordelikheid van die provinsiale administrasies, maar weens ontoereikende fasiliteite kon hulle nog nie sulke dienste in al hierdie gebiede implementeer nie.

Departementele verpleegkundiges lewer dus die volgende dienste in artikel 30-gebiede:

voorgeboortesorg met verwysing vir kraam;

- gesinsbeplanning;

- nageboortesorg;

- gesondheidsbevorderende klinieke vir babas en voorskoolse kinders;

— immunisering volgens Departementele skedule;

- tuberkulosebeheer met klem op gevalopsporing, behandeling onder toesig en B.C.G.-toediening;

- monitor van leprapasiënte;

- opsporing en behandeling van pasiënte met aansteeklike siektes en hul kontakte;

- bekamping van voedingsgebreksiektes;

- behandeling van geringe ongesteldhede;

- kontrolering en verwysing van psigiatriese pasiënte;

- voorkomende en bevorderende be jaardesorgdiens:

- skoolgesondheidsdiens sonder spesialisasie;

- geprogrammeerde gesondheidsvoorligting:

- geordende selektiewe tuisbesoeke;

- identifisering van en optrede om probleme ten opsigte van watervoorsiening, afvalverwydering en behuising op te los;

- gemeenskapsbetrokken heidsprojekte 


\section{UITDAGING}

Landelike gesondheidsorgprobleme is uiters kompleks van aard. Politieke, finansiële sowel as emosionele dryfvere is daarby betrokke en moet by die beplanning van dienste in ag geneem word. In sekere opsigte is die diens uniek en eiesoortig. Tegnieke en norme wat elders suksesvol in P.G.S.-dienste toegepas word, kan hier nie geredelik geimplementeer word nie.

\section{Die teikengroep}

Die teikengroepe bestaan grotendeels uit plaasarbeiders (dikwels trek- of seisoenarbeiders) en hulle gesinne.

Die sogenoemde village worker wat elders suksesvol by P.G.S.-dienste betrek word, kan nie geredelik gewerf word nie. Tradisioneel betaal die gemeenskap die salaris van so 'n werker wat deur hulself uit eie geledere benoem is. In klein gemeenskappe van plaaswerknemers, bestaande uit enkele gesinne, is hierdie beginsel dikwels nie uitvoerbaar nie. Huidiglik ontbreek hierdie skakel in die ketting van P.G.S.dienste dus in die meeste artikel 30-gebiede.

\section{Infrastruktuur}

\section{Diagram 1: Die Ideale Infrastruktuur waarin PGS-dienste gelewer be- hoort te word.}

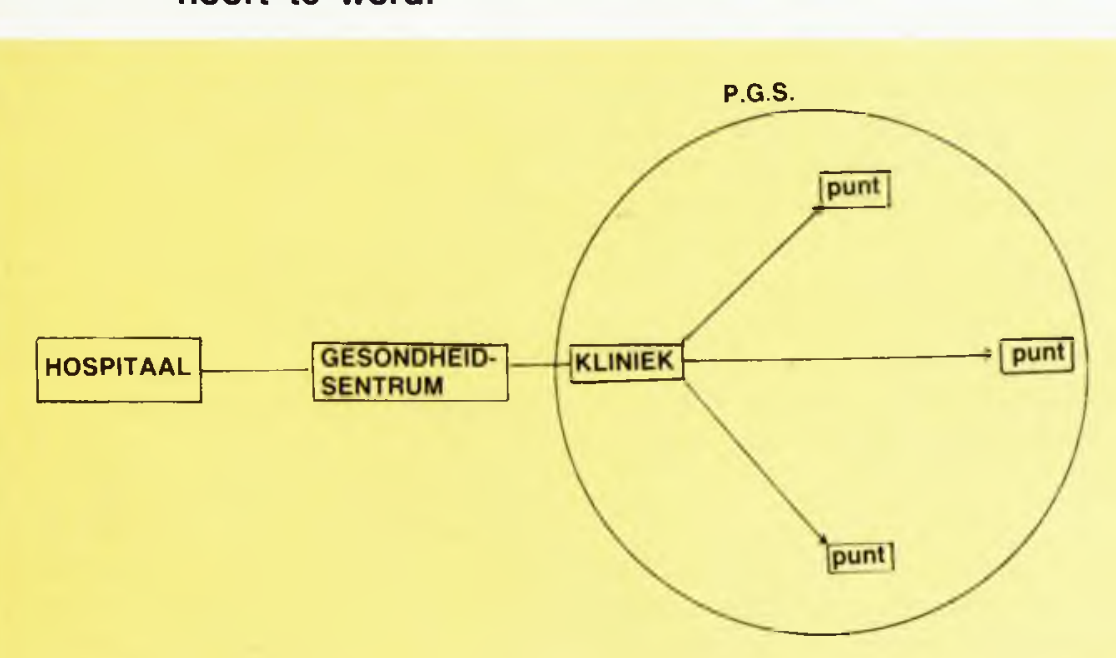

Diagram 1 illustreer ' $n$ ideale infrastruktuur waarin P.G.S.-dienste gelewer behoort te word.

Om verskeie redes, onder andere die stelsel van drie owerheidsvlakke wat huidiglik nog verantwoordelik is vir verskillende aspekte van gesondheidsorg in die Republiek van Suid-Afrika, bestaan so 'n struktuur nog nie in artikel 30-gebiede nie.

Die werklike situasie, met geringe plaaslike wisseling, kan skematies voornie. Sy praktiseer dus in 'n groot mate

en raadgewer, in die Departementele struktuur, is gewoonlik baie kilometers ver elders gestasioneer.

Inligting omtrent die gebiede, die mense en hul siektepatrone is ontoereikend.

\section{Diagram 2: Die infrastruktuur waarin PGS-dienste in Artikel 30-ge- biede gelewer word.}

PROVINSIE

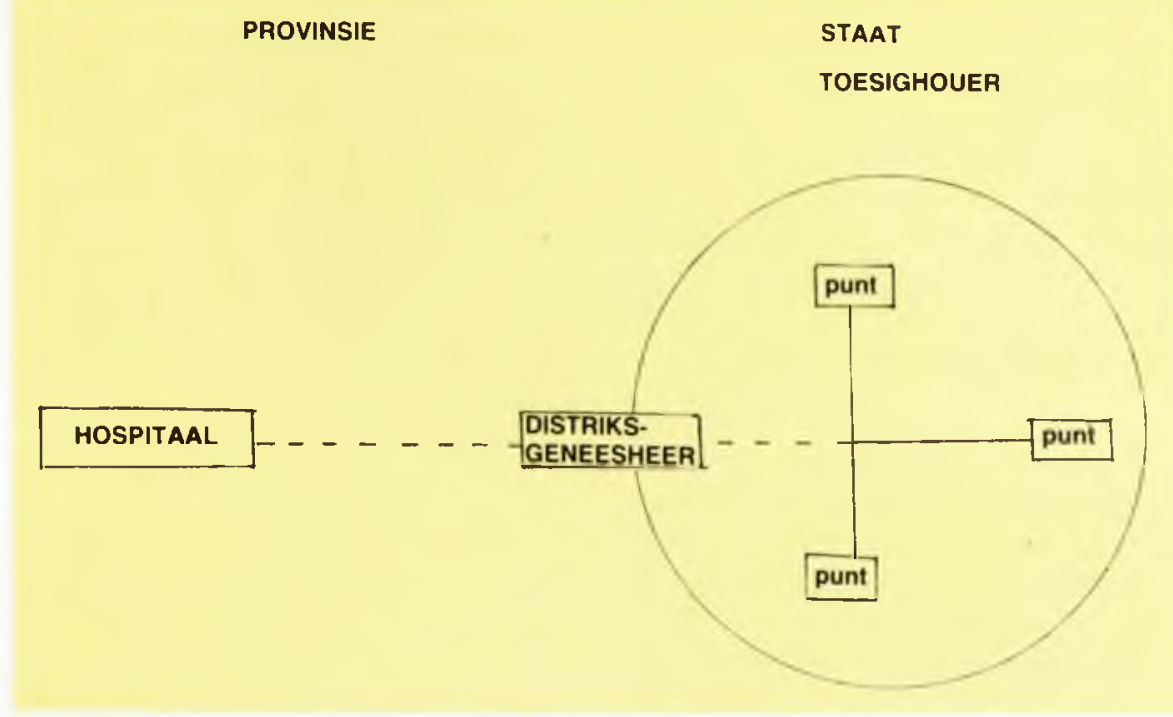

2 .

Die verpleegkundige het dus nie kliniekfasiliteite met ondersteunende mediese dienste vir direkte skakeling en verwysing nie. Sy beskik ook nie oor maklik bereikbare verwysingsbronne onafhanklik en is op haarself aangewese. Haar onmiddellike toesighouer

\section{Demografiese data en siektepro- fiel}

Die gebrek aan beskikbare data kan aanleiding gee tot foutiewe besluitne- ming wat 'n uiters negatiewe invloed op die diens mag hê. Dit is vanselfsprekend dat die gebrek aan gesondheidstatistiek in die betrokke gebiede sinvolle prioriteitsbepaling sal bemoeilik. Geboorteen kindersterftesyfers is merendeels onvolledig, selfs onbekend. So ook die voorkomssyfers van tuberkulose, voedinggebreksiektes en masels, om enkele voorbeelde te noem. Pasiënte meld dikwels eers wanneer die siektetoestand ver gevorderd is vir behandeling aan.

In 'n situasie waar dienste volgens plaaslike behoeftes gelewer moet word, lik nie beskikbaar nie.

Die verpleegkundige moet self deur persoonlike kontak en bereising van haar gebied die siektepatrone en gewoontes van die gemeenskap bepaal. Sy moet planmatig motivering doen om registrasie van geboortes en sterftes te bewerkstellig. Sy moet kommunikasiekanale daarstel om aanmelding van bepaalde siektetoestande te vergemaklik.

\section{Voorlopige norme}

'n Behoeftebepaling het getoon dat 'n bevolking van 4250000 persone op hierdie dienste aangewese is. Min of geen ander gesondheidsdienste is binne bereik van hierdie gemeenskappe nie.

Daar is verder beraam dat in so 'n gebied met min of geen gesondheidsdienste nie, ten minste twee kontakte per persoon per jaar wenslik is. Volgens 'n steekproef wat uitgevoer is, kan een bedien as sy 'n omvattende P.G.S.diens in so 'n gebied sou verskaf.

Bogenoemde is nie ' $n$ bevredigende is die gesondheidsprofiel dus aanvankverpleegkundige 'n bevolking van 3000 
wyse om doelstellings te bepaal en vooruit te beraam nie. Dit neem nie plaaslike omstandighede en siektepatrone in ag nie. Dog juis weens gebrekkige aanvanklike statistiek word poste huidiglik volgens hierdie norm beplan.

Poste word ontplooi waar die digste bevolkings aangetref word om sodoende koste-effektiwiteit te bewerkstellig.

\section{Beplanning van dienste}

- Roetes en dienspunte word met sorg beplan ten einde die reistyd tot die minimum te beperk en soveel persone moontlik op elke punt te bedien. Die samewerking van boere (as werkgewers), die topografie van die gebied en die bereikbaarheid of beskikbaarheid van fasiliteite is onder andere bepalende faktore in hierdie verband.

- Goed toegeruste mobiele eenhede word geleidelik beskikbaar gestel maar in die tussentyd word baie van hierdie dienste uit motors gelewer - dikwels Volkswagen-kewers.

- Fisiese fasiliteite is selde beskikbaar. Die dienspunt is dikwels 'n boom, die landerye waar werknemers besig is om te oes, 'n hut of - absolute weelde - 'n plaasskool.

Dit is 'n uitdaging om in sulke omstandighede diens van gehalte te lewer. Die verpleegkundige moet met vernuf en vindingrykheid 'n mate van privaatheid, respek en vertroulikheid bewerkstellig.

\section{Tegnologie}

Wanneer primêre gesondheidsorgdienste na 'n ontwikkelende gemeenskap geneem word, kan bekende, gesofistikeerde tegnieke nie summier oorgeplant word nie. Wat in die een situasie doeltreffend is, is nie noodwendig geslaagd of prakties in ' $n$ ander nie.

Daar moet 'n keuse gemaak word uit die verskeidenheid toerusting, tegnieke en prosedures waarmee die beroep reeds vertroud is. In sekere gevalle sal dit nodig wees om totaal nuwe metodes te bedink. Keuses is onderworpe aan finansiële, politieke en maatskaplike kriteria. Veiligheid en doeltreffendheid moet ook in ag geneem word. Gesondheidsaksies en gesondheidstegnologie moet in plaaslike behoeftes voorsien.

Gesondheidstegnologie behels die kompleksiteit van metodes, benutting van toerusting, profilaktiese, diagnostiese of terapeutiese stowwe, of enige ander hulpmiddel wat nodig mag wees.

Daar moet gekyk word na tegnieke wat aan die biomediese en gesondheidswetenskappe ontleen is, asook dié wat met die opleiding, kommunikasie, opvoeding van die gemeenskap of wysiging van die sosiale en fisiese omgewing gemoeid is. En daar moet altyd gesoek word na dit wat 'n balans tussen effektiwiteit, koste en aanvaarbaarheid sal bewerkstellig.

Verpleging vandag behels onder andere toepaslike sorg met toepaslike toerusting, metodes en tegnieke. Nêrens is die uitdaging groter as juis in sulke plattelandse gebiede nie.

In die soeke na antwoorde is ondersoekende denke, insigryke waarnemings en innoverende verbeelding nodig.

\section{Samewerking met sleutelgroepe}

Die sukses van hierdie dienste word deur die samewerking van verskeie sleutelgroepe en persone bepaal en is afhanklik van die wyse waarop hulle dit vertolk, aanvaar of verwerp.

\section{Die boer as werkgewer}

Die boer moet oortuig word van die waarde van die dienste vir sy werknemers en dus ook vir homself. Hy moet die werknemer en sy gesin in staat stel om die dienste te benut en vir hom is tyd sowel as vervoer na dienspunte op die spel. Waar nodig moet hy ook van die noodsaaklikheid van 'n sindelike omgewing en genoeg veilige water vir sy werknemers en hul gesinne oortuig word.

Ook die boervrou speel 'n belangrike rol in die verbetering van die lewensgehalte van die werknemers. Groot sukses is reeds behaal met projekte waarby plaasvroue betrek is, byvoorbeeld by die daarstelling van groentetuine asook higiëne- en voedingsvoorligting in die woongebied van werknemers. Gemotiveerde plaasvroue betrek weer hul vriendinne sodat die essensiële element van gemeenskapsbetrokkenheid steeds verder uitkring.

\section{Geneeshere en Aptekers}

Ongelukkig is sommige geneeshere en aptekers hierdie dienste nie goedgesind nie. Geneeshere het al beswaar gemaak omdat hulle sedert die instelling van die voorkomende en bevorderende dienste in hul omgewing, veel minder siek kinders sien.

Miskien is Gesondheid vir almal teen die jaar 2000 'n moeilik bereikbare doelwit. Maar gesondheidsdienste vir almal is sekerlik 'n realistiese gemeenskaplike doel vir al die gesondheidsprofessies.

Dit is die verpleegkundige se taak om sulke weerstand te oorwin en om sinvolle wedersydse verwysing en kommunikasie te bewerkstellig in belang van die gemeenskap wat op die gesondheidsdienste aanspraak maak.

\section{Ander}

Om die diens aanvaarbaar te maak sodat dit ten volle benut word, is dit ook nodig om die volle samewerking van landdroste, skoolhoofde en kringinspekteurs van skooldienste te verkry.

\section{Onafhanklike state}

Dikwels is die naaste hospitaalfasiliteite in 'n naburige onafhanklike staat geleë. In so 'n geval moet daar samewerking ten opsigte van wedersydse verwysing asook ambulansdienste verkry word.

\section{Die plaasarbeider en sy gesin}

Die ervaring is dat waar 'n P.G.S.-diens geïmplementeer word, die gemeenskap se aanvanklike behoefte veral dié aan 'n kuratiewe diens is, juis omdat sulke dienste nie geredelik beskikbaar was nie.

Dit verg tyd, geduld en deurlopende gesondheidsvoorligting om die waarde en belang van voorkomende en bevorderende dienste tuis te bring.

Aanvanklik val die klem dan ook op immunisering en die behandeling van geringe ongesteldhede. Geleidelik kry die deurlopende voorligting en gemeenskapsontwikkelingsprojek momentum en uiteindelik word 'n omvattende diens aangebied, met die klem op bevordering van gesondheid en voorkoming van ongesteldhede.

Die aard van die diens moet só wees dat die gemeenskap vertroue daarin sal hê. Dit moet sensitief wees vir behoeftes. Dit moet geredelik bereikbaar en deurlopend van karakter wees. Elemente van hulpverlening, raadgewing en ondersteuning moet teenwoordig wees. Veral moet die gemeenskap betrokke wees en deelname hê aan die beplanning van die diens 


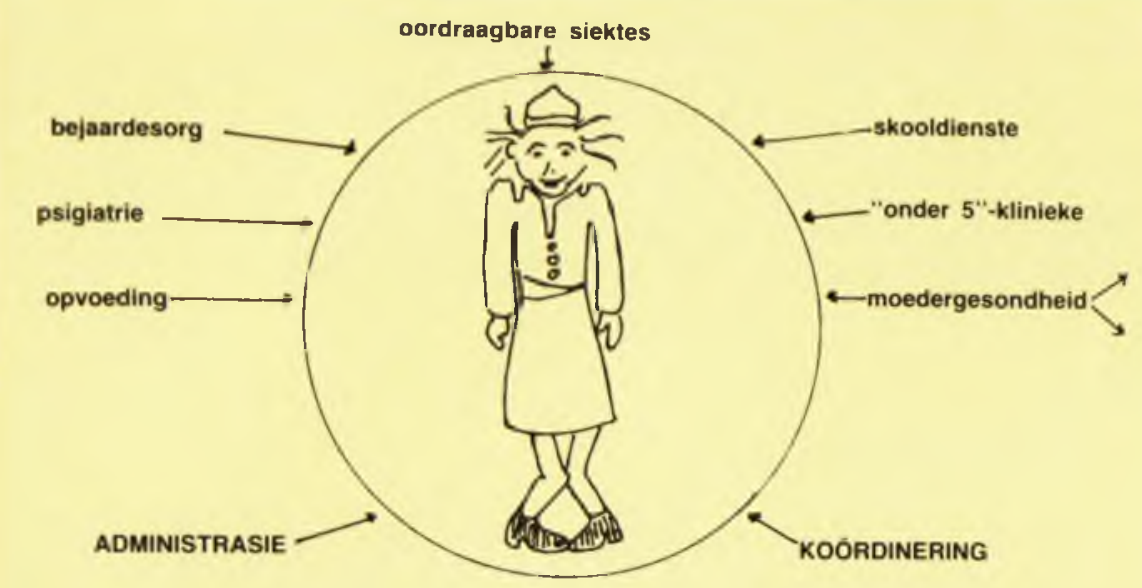

\section{Die taak van die verpleegkundige}

In 'n tydvak van toenemende spesialisering en gevolglike fragmentering van die pasiënt, word van hierdie verpleegkundige verwag om 'n toonbeeld van veelsydigheid te wees, soos geillustreer in Diagram 3.

Sy word in ' $n$ braak gebied afgelaai met die opdrag om 'n omvattende diens aan gesinne en gemeenskappe te lewer. In haar Volkswagen moet sy soos 'n pionier van ouds haarself en haar diens gaan verkoop - aan boere, werkgewers, arbeiders en oumas; aan skoolhoofde, indoenas en vroueorganisasies; aan geneeshere en aptekers. Wind, weer, slaggate, plaashekke en pap wiele ontmoedig haar nie. 'n Enorme werkslading, powere fasiliteite en lang ure sterk net haar vasbeslotenheid en geloof.

Met veranderde omstandighede en nuwe tendense het die onafhanklike funksie van die verpleegkundige - tereg - uitgebrei. Talle omstrede kwessies raak hierdie rol - veral waar sy 'n gemeenskap moet bedien sonder direkte mediese dekking en met slegs afstandverpleegbeheer. Daar is onder andere die nie-aanvaarding van haar uitgebreide rol deur die mediese professie asook die wetlike beperkings van die Wet op Geneeshere, Tandartse en Aanvullende Gesondheidsberoepe 56 van 1974 en die Wet op die Beheer van Medisynes en Verwante Stowwe 101 van 1965. Die Wysigingswet op Verpleging, 71 van 1981 is 'n poging om hierdie knelpunte uit te skakel -- 'n stap wat noodsaaklik is as gesondheidsdienste geredelik beskikbaar gemaak moet word aan plattelandse gemeenskappe.

Daar moet opnuut besin word oor die dokter-verpleegsterverhouding. Samewerking is essensieel as die totale welsyn van die mens, en nie net die behandeling van sy siektetoestand, die erns van die gesondheidsprofessies is nie.

\section{Bekombaarheid van verpleeg- mannekrag}

Daar is tans nie alleenlik 'n tekort aan verpleegkundiges nie, maar ook 'n wanverspreiding sodat toepaslik opgeleide verpleegkundiges moeilik vir plattelandse gebiede gewerf word.

Op 31-12-1980 was 55022 verpleegkundiges by die Suid-Afrikaanse Raad op Verpleging geregistreer. Van hulle het 2760 of $5 \%$, oor 'n kwalifikasie in

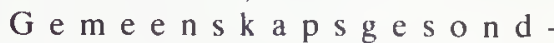
heidsverpleegkunde beskik. Van hulle was slegs $5 \%$ in diens van die Departement. Soos reeds aangedui, word die Departement se poste veral op die platteland benut. Van departementele poste vir gemeenskapsgesondheidsverpleegkundiges in plattelandse gebiede, was slegs $30 \%$ toepaslik gevul. Die betrokke dienste word dus in baie gevalle gelewer deur verpleegkundiges sonder hierdie addisionele kwalifikasie.

Verpleegkundiges wat in artikel 30gebiede diens lewer, word planmatig in die werksituasie opgelei en toegerus om diens van gehalte te kan lewer.

\section{SLOT}

Hierdie dienste, word geglo, sal geregverdig word deur die enigste maatstaf wat saak maak, te wete, positiewe resultate. By wyse van gesondheidsdienste beteken dit ' $n$ veelbetekenende bydrae tot die gehalte en waardigheid van die mens se bestaan.

\section{BIBLIOGRAFIE}

1. Kotze. A.J. Die ontwikkeling van die taak van die verpleegster in die lewering van primêre gesondheidsorg. Ongepubliseerde verhandeling vir Magister Curationi (Verpleegonderwys). Universiteit van Pretoria.

2. Skeet. Muriel. Building on what they have. Nursing Mirror. Vol 152 No 21. May 20, 1981

3. Spencer, I.W.F. Community Healh. Shuter and Shuter Pietermaritzhurg, 1980

4. World Health Organisation. Technical Report Series $N$ 350: National Health Planning in Developing Countries WHO. Geneva. 1967

\section{BOOK REVIEW BOEKRESENSIE}

\section{FATHERING - PARTICIPATION IN LABOUR AND BIRTH}

\section{by Celeste R. Phillips and Joseph T. Anzalone}

\section{C.V. Mosby. St. Louis. 1978.}

This clearly written, well illustrated book focuses primarily on the father and his involvement with labour and birth.

The book is divided into the following sections:

Unit I The Prospective Father

This section deals with the father's participation in labour and birth and the benefits thereof and his role in childrearing.
Unit II The Physician's Viewpoint.

This unit reflects the views of one of the authors and outlines the advantages and disadvantages of the father's presence in the delivery room as well as the need for childbirth preparation classes.

Unit III Discusses the needs of all members of an expectant family, i.e. family centred care.

Unit IV A brief collection of MEMORIES retold by the fathers, looking at Birth in Retrospect

M. ABSOLOM 